\title{
Zoledronic Acid-Induced Acute Renal Failure in Multiple Myeloma
}

\author{
Salem Bouomrani ${ }^{1,2 *}$, Nesrine Regaïeg ${ }^{1}$, Marwa Nefoussi ${ }^{1}$ and Safa Trabelsi ${ }^{1}$ \\ ${ }^{1}$ Department of Internal Medicine, Military Hospital of Gabes, Tunisia \\ ${ }^{2}$ Department of Medicine, University of Sfax, Tunisia
}

Submission: October 27, 2018; Published: November 05, 2018

*Corresponding author: Salem Bouomrani, Department of Internal Medicine, Military Hospital of Gabes, Gabes 6000, Tunisia

\begin{abstract}
Introduction: Despite its potential severity, the renal toxicity induced by zoledronate acid (ZA) is poorly studied and little characterized in current medical practice. Acute renal failure with zoledronate in multiple myeloma (MM) has only been reported by a few authors as sporadic cases. We are reporting an original observation of ZA-induced early nephrotoxicity during MM treatment.

Case report: A 74-year-old female, with no notable pathological history, was explored for recent deterioration of the general condition with diffuse inflammatory rachialgia and bone pain. Investigations concluded to the diagnosis of IgG lambda Durie-Salmon stage IIIA MM. She was treated with six courses of melphalan-prednisolone-thalidomide (MPT) chemotherapy with a favorable initial outcome. The subsequent evolution was marked by the occurrence of two episodes of progression that were treated with two cycles of six MPT courses. Monthly infusions of ZA (Zometa ${ }^{\circledR}$ ) at a dose of $4 \mathrm{mg}$ were prescribed for very painful bone metastases. When admitted for the third infusion, the assessment noted acute renal failure with creatinine at $279 \mu \mathrm{mol} / \mathrm{l}$. Stopping Zometa ${ }^{\circledR}$ and adequate hydration allowed gradual normalization of renal function with creatinine at $194 \mu \mathrm{mol} / \mathrm{l}$ after one week, $115 \mu \mathrm{mol} / \mathrm{l}$ after one month, and $83 \mu \mathrm{mol} / \mathrm{l}$ after two months.
\end{abstract}

Conclusion: ZA should be used with caution in MM, and regular monitoring of renal function is recommended. These measures are particularly useful if frequent administration of this drug, associated risk factors, and pre-existing renal lesions.

Keywords: Zoledronic acid; Zoledronate; Acute renal failure; Nephrotoxicity; Multiple myeloma

Abbreviations: ZA: zoledronate acid; MM: Multiple Myeloma; MPT: Melphalan-Prednisolone-Thalidomide; FDA: Food and Drug Administration

\section{Introduction}

Intravenous bisphosphonates are increasingly used in cancerous pathology to prevent acute osteolytic complications and treat hypercalcemia of malignancy. Nephrotoxicity represents a potentially serious and sometimes limiting complication of this use [1,2]. This complication is variable from one molecule to another [3] and seems to be dose- and durationdependent $[1,2,4,5]$.

Zoledronic acid (ZA) is a bisphosphonate that has been shown to be effective in preventing, reducing the incidence, and delaying the occurrence of bone events in cancer patients, as well as controlling bone pain $[5,6]$.

It is characterized, moreover, by a widely established tolerance, allowing its long-term admission in a safe way [6]. However, preventive measures are necessary during longterm administration to avoid certain serious but exceptional complications, such as nephrotoxicity and osteonecrosis of the jaw $[6,7]$. Despite its potential severity, the renal toxicity induced by ZA is little known, poorly studied, and little characterized in current medical practice [8].
Acute renal failure with Zoledronate in multiple myeloma (MM) has only been reported by a few authors as sporadic cases. We report an original observation of ZA-induced early nephrotoxicity during MM treatment.

\section{Case Report}

A 74-year-old female patient, with no notable pathological history, was explored for recent deterioration of the general condition with diffuse inflammatory rachialgia and bone pain.

The biological assessment showed normochromic normocytic anemia at $8 \mathrm{~g} / \mathrm{dl}$ without thrombocytopenia or leukopenia, erythrocyte sedimentation rate at $140 \mathrm{mmH}$, C-reactive protein at $52 \mathrm{mg} / \mathrm{l}$, hyperprotein at $132 \mathrm{~g} / \mathrm{l}$ with a proteinuria of 24 hours at $0.7 \mathrm{~g}$, calcemia at $2.68 \mathrm{mmol} / \mathrm{l}$, and hyperuricemia at $740 \mu \mathrm{mol} / \mathrm{l}$. Plasma protein electrophoresis revealed monoclonal hypergammaglobulinemia at $62 \mathrm{~g} / \mathrm{l}$ with suppression of other proteins. Renal function was normal with creatinine at $89 \mu \mathrm{mol} / \mathrm{l}$.

Immunoelectrophoresis of the blood proteins isolated monoclonal IgG gammopathy and urinary 
immunoelectrophoresis showed free and bound monoclonal lambda light chains. Standard radiographs of long bones, pelvis, thoracolumbar spine, and skull showed multiple geodic lytic lesions. The myelogram confirmed the diagnosis of MM by showing bone marrow infiltration by $28 \%$ of dystrophic plasma cells.

Nuclear magnetic resonance imaging did not objectify epiduritis or medullary compression. At the end of this assessment, the diagnosis of IgG lambda Durie-Salmon stage IIIA MM was retained. She was treated with six courses of melphalan-prednisolone-thalidomide (MPT) chemotherapy with a favorable initial outcome (response evaluated at $80 \%$ ).

The subsequent evolution was marked by the occurrence of two episodes of progression after two and three years that were treated with two cycles of six MPT courses, followed by maintenance treatment with thalidomide. Monthly infusions of zoledronic acid (Zometa $\AA$ ) at a dose of $4 \mathrm{mg}$ were prescribed for very painful bone metastases. When admitted for the third infusion, the assessment noted a blood creatinine at $279 \mu \mathrm{mol} / \mathrm{l}$ without evidence of dehydration, urinary tract infection, associated hypercalcemia, or rhabdomyolysis. Renal ultrasound and Doppler examination of renal vessels were without abnormalities. Stopping Zometa ${ }^{\circledR}$ and adequate hydration allowed gradual normalization of renal function with creatinine at $194 \mu \mathrm{mol} / \mathrm{l}$ after one week, $115 \mu \mathrm{mol} / \mathrm{l}$ after one month, and $83 \mu \mathrm{mol} / \mathrm{l}$ after two months.

\section{Discussion}

Nephrotoxicity does not complicate oral bisphosphonates used in the treatment of osteoporosis; it complicates only intravenous bisphosphonates used in the treatment of bone metastases and severe hypercalcemia $[1,9]$.

Regardless of the intravenous bisphosphonate used, the clinical and simple laboratory evaluation (based only in serum creatinine assay) largely underestimates the frequency of this complication; Systematic screening in Phase III large clinical trials estimated the incidence of bisphosphonate-induced kidney damage at 7.7 to $15.2 \%$ depending on the dose of the drug used for infusion ( 4 or $8 \mathrm{mg}$ ) and depending on the underlying neoplasia $(7.7 \%$ for breast cancer, $10.7 \%$ for multiple myeloma and breast cancer, and $15.2 \%$ for prostate cancer) [7].

Conversely, in the experimental animal study, $100 \%$ of rats presented histological renal lesions after intravenous bisphosphonate therapy [10]. These lesions were basal membrane thickness, cytoplasmic vacuolization, loss of brush border, tubular epithelial smoothness, tubular lumen obstruction and cell necrosis [10].

In humans, similar lesions such as loss of brush border, tubular degeneration with luminal ectasia, tubular atrophy, interstitial fibrosis, hypereosinophilia, and inflammation were also observed on histological examination of renal biopsies in patients with acute tubular necrosis under zoledronate [8].
This nephrotoxicity remains exceptional with ZA in large series: only $0.02 \%$ in the American series of Chang JT et al of 430,000 cancer patients receiving zoledronate [4]. Similarly, the French Adverse Event Reporting System database reported only seven cases over a period of four years following the introduction of this drug in the country [5], and no case was noted in Sabry NA et al series of 40 cancer patients receiving this treatment at usual doses and monitored over three months [11].

The clinical spectrum of this nephrotoxicity includes acute renal tubular necrosis, collapsing focal segmental glomerulosclerosis, acute renal failure, deterioration of preexisting chronic renal failure, interstitial nephritis, nephrotic syndrome, tubulopathies, and Fanconi syndrome $[1,5,8,12]$.

The risk factors for ZA-induced nephrotoxicity are: advanced cancer, MM, pre-existing renal insufficiency, diabetes, hypertension, severe dehydration, rapid infusion of the drug ( $<15$ minutes), and concomitant use of other nephrotoxic drugs $[4,5]$.

This nephrotoxicity occurs at variable intervals compared with the start of treatment with bisphosphonates (1-120 days) [5]. It appears to be dose- and infusion duration-dependent (1.5) but may also occur early and even after a single infusion of the drug, and without any risk factors favoring it [13].

MM seems to be particularly predisposing to zoledronateinduced nephrotoxicity; in fact, five out of six patients who developed renal insufficiency (related to acute tubular necrosis) caused by zoledronate in the Markowitz CS et al. [8] series were myelomatous. Similarly, in American cases of ZA-induced nephrotoxicity reported by the Food and Drug Administration (FDA), 42 patients/72 were myelomatous (58.3\%) [4].

However, it seems that other factors, particularly genetic/ ethnic, intervene in this nephrotioxicity; indeed, no case of renal damage has been reported in the Teoh G et al series of 44 Asian patients with MM receiving ZA intravenously and at usual doses [14].

The mechanisms evoked for this nephrotoxicity are: the aggregation of bisphosphonates and calcium complexes in renal cells, and even more the induction by bisphosphonates of renal tubular cell death (similar to their apoptotic effect on osteoclasts) [10]. This is particularly due to the renal uptake and elimination of bisphosphonates [15]. Acute renal failure with zoledronate in MM has only been reported by a few authors as sporadic cases [16-18].

Usually zoledronate-induced renal damage is reversible when the bisphosphonate is stopped $100 \%$ reversibility in the Markowitz GS et al. [8] series) [5,8]. However, recovery of renal function after stopping treatment may not be complete [5], and even fatal outcomes of this nephrotoxicity have been reported [5]: of the 72 American cases, 27 required dialysis and 18 decided [4]. 
Concomitant administration of vitamin E (15mg/week intramuscularly) significantly reduces the nephrotoxicity of ZA as demonstrated by the experimental animal study of Serti IU et al. [10].

\section{Conclusion}

ZA should be used with caution in MM, and regular monitoring of renal function, especially tubular function, is recommended in any patient receiving zoledronate. These measures are particularly useful if frequent administration of this drug, associated risk factors, and pre-existing renal lesions. The monitoring of creatinine before each infusion, the good hydration, the temporary suspension of infusions in case of occurrence of nephropathy, and the adjustment of the doses of the bisphosphonate in case of pre-existing nephropathy are the only guarantors to avoid this potentially fatal complication of bisphosphonates.

\section{References}

1. Perazella MA, Markowitz GS (2008) Bisphosphonate nephrotoxicity. Kidney Int 74(11): 1385-1393.

2. Pozzi S, Raje N (2011) The role of bisphosphonates in multiple myeloma: mechanisms, side effects, and the future. Oncologist 16(5): 651-662.

3. Luedders DW, Steinhoff J, Thill M, Rody A, Bohlmann MK (2015) Lack of difference in acute nephrotoxicity of intravenous bisphosphonates zoledronic acid and ibandronate in women with breast cancer and bone metastases. Anticancer Res 35(3): 1797-1802.

4. Chang JT, Green L, Beitz J (2003) Renal failure with use of zoledronic acid. N Engl J Med 349: 1676-1678.

5. Munier A, Gras V, Andrejak M, Bernard N, Jean-Pastor MJ, et al. (2005) Zoledronic Acid and renal toxicity: data from French adverse effect reporting database. Ann Pharmacother 39(7-8): 1194-1197.

6. Isla D, Afonso R, Bosch-Barrera J, Martínez N (2013) Zoledronic acid in lung cancer with bone metastases: a review. Expert Rev Anticancer Ther 13(4): 421-426.

This work is licensed under Creative Commons Attribution 4.0 License DOI: 10.19080/JOJCS.2018.09.555757
7. Hirschberg R (2012) Renal complications from bisphosphonate treatment. Curr Opin Support Palliat Care 6(3): 342-347.

8. Markowitz GS, Fine PL, Stack JI, Kunis CL, Radhakrishnan J, et al. (2003) Toxic acute tubular necrosis following treatment with zoledronate (Zometa). Kidney Int. 64(1): 281-289.

9. Miller PD (2011) The kidney and bisphosphonates. Bone 49(1): 77-81.

10. Sert IU, Kilic O, Akand M, Saglik L, Avunduk MC, et al. (2018) The role of vitamin $\mathrm{E}$ in the prevention of zoledronic acid-induced nephrotoxicity in rats: a light and electron microscopy study. Arch Med Sci 14(2): 381387.

11. Sabry NA, Habib EE (2011) Zoledronic acid and clodronate in the treatment of malignant bone metastases with hypercalcaemia; efficacy and safety comparative study. Med Oncol 28(2): 584-590.

12. Torimoto K, Okada Y, Arao T, Mori H, Tanaka Y (2012) A case of zoledronate-induced tubulointerstitial nephritis with Fanconi syndrome. Endocr J 59(12): 1051-1056.

13. Yachoui R (2016) Early onset acute tubular necrosis following single infusion of zoledronate. Clin Cases Miner Bone Metab 13(2): 154-156.

14. Teoh G, Chen Y, Kim K, Srivastava A, Pai VR, et al. (2012) Lower dose dexamethasone/thalidomide and zoledronic acid every 3 weeks in previously untreated multiple myeloma. Clin Lymphoma Myeloma Leuk 12(2): 118-126.

15. Bergner R, Diel IJ, Henrich D, Hoffmann M, Uppenkamp M (2006) Differences in nephrotoxicity of intravenous bisphosphonates for the treatment of malignancy-related bone disease. Onkologie 29(11): 534540 .

16. Henley D, Kaye J, Walsh J, Cull G (2005) Symptomatic hypocalcaemia and renal impairment associated with bisphosphonate treatment in patients with multiple myeloma. Intern Med J 35(12): 726-728.

17. Koike K, Morishige S, Fukami K, Taguchi K, Yakushiji K, et al. (2011) Case report; a case of acute kidney injury due to intravenous zoledronic acid hydrate, improved with bortezomib plus dexamethazone therapy in a patient with multiple myeloma. Nihon Naika Gakkai Zasshi 100(1): 179-181.

18. Bodmer M, Amico P, Mihatsch MJ, Haschke M, Kummer O, et al. (2007) Focal segmental glomerulosclerosis associated with longterm treatment with zoledronate in a myeloma patient. Nephrol Dial Transplant 22(8): 2366-2370.

\section{Your next submission with Juniper Publishers will reach you the below assets}

- Quality Editorial service

- Swift Peer Review

- Reprints availability

- E-prints Service

- Manuscript Podcast for convenient understanding

- Global attainment for your research

- Manuscript accessibility in different formats

( Pdf, E-pub, Full Text, Audio)

- Unceasing customer service

Track the below URL for one-step submission

https://juniperpublishers.com/online-submission.php 